\title{
Time to halt the overprescribing of proton pump inhibitor therapy
}

\section{Daniel JB Marks}

Proton pump inhibitors (PPIs) are among the most frequently prescribed drugs globally. While they are highly cost-effective when used appropriately, studies across a wide range of populations continue to identify that they are prescribed without a clear indication in up to $70 \%$ of cases. This results in a cost to the NHS in excess of $£ 100 \mathrm{~m}$ each year ${ }^{1}$. In addition, although the absolute risk of harm to individuals from PPIs is low, their widespread long-term use is accompanied by a number of adverse effects that contribute significant negative impacts at a population level. Action is now required to limit the inappropriate prescribing of PPIs, and support deprescribing in patients on long-term therapy in whom the original indications no longer apply.

\section{The rise of PPIs}

PPIs were introduced in the 1980s, and rapidly became some of the best-selling medicines of all time. They inhibit gastric acid secretion through blockade of $\mathrm{H}^{+} / \mathrm{K}^{+}$-ATPases in parietal cells, and are highly effective for treating peptic ulceration, oesophagitis and gastro-oesophageal reflux ${ }^{2,3}$. They are also important components of Helicobacter pylori eradication regimens ${ }^{4}$, and useful for prophylaxis against non-steroidal anti-inflammatory drug (NSAID) induced upper gastrointestinal injury 5 . For most of these presentations, they are only intended for short-term use and rarely required beyond four to eight weeks. In a minority of conditions (for example, severe Barrett's oesophagus, gastrinoma and eosinophilic oesophagitis), protracted courses may be required 6 .

PPIs combine high efficacy with low toxicity, and are perceived to be safe and cost-effective ${ }^{1}$. Consequently, they are widely prescribed. Their use costs the NHS over $£ 100 \mathrm{~m}$, and global spend is in excess of $€ 2 \mathrm{bn}$. Five PPIs are currently licensed in the UK: omeprazole, lansoprazole, pantoprazole, esomeprazole and rabeprazole. In most scenarios, there is no clear evidence to support use of one over another, and class effects can be assumed ${ }^{7}$.

\section{Overprescribing is the norm}

Studies consistently find that PPIs are overprescribed, globally, in both primary and secondary care. Their prevalence continues to increase: in Australia, prescriptions rose by $1318 \%$ over one decade 8 . Most of this occurs in primary care, with increasing numbers treated for longer durations ${ }^{9}$. Part of this relates to substitution of histamine- 2 receptor antagonists, but the bulk represents expanded use of acid suppression therapy. A proportion of this increase will be legitimate, due to rising groups of patients treated with dual antiplatelet therapy for coronary artery or cerebrovascular disease, or bisphosphonates (for which PPIs partially mitigate risk of oesophagitis ${ }^{10}$ ). There is also a small cohort of patients with chronic cough in whom gastro-oesophageal reflux is believed to be a contributor ${ }^{11}$. The recent approvals of esomeprazole for general sale, and 
pantoprazole as an over-the-counter medicine, may further drive consumer use in the UK.

A number of studies have examined the appropriateness of PPI prescriptions. In one series looking at medicines in elderly patients in Italy, $30 \%$ were receiving a PPI with no clear indication, although a further $11 \%$ of this cohort possessed a recognised indication and were not on treatment (that is, PPIs were underprescribed) ${ }^{12}$. A study of 124,133 first-time adult users from Denmark found that only one-third met criteria for potential long-term use, and that there were significant variations in initiating such therapy related to both patient and prescriber characteristics ${ }^{13}$. In contrast, in the same catchment population, only $4 \%$ of pre-existing long-term users (defined as more than 60 daily doses over a six-month period) had a diagnosis that overtly merited such management ${ }^{14}$.

Within hospitals, a retrospective study of surgical inpatients from The Netherlands identified non-compliance with guidelines in $46.6 \%$; $93.1 \%$ of these represented overprescribing ${ }^{15}$. Audits of medical inpatients in the UK show inappropriate prescribing rates of $40.7-54 \%$, of which $86 \%$ are overprescribing. ${ }^{16,17}$ Data from other countries are comparable, associated with substantial costs ${ }^{8,18-21}$.

A number of studies have probed the underlying rationales for PPI prescription and their continued use $\mathrm{e}^{22-24}$. The reasons are frequently questionable, and adherence to guidelines poor with behaviour challenging to adapt despite educational and stewardship strategies ${ }^{25}$. The most common explanations were inappropriate treatment of dyspepsia, prophylaxis for low-risk patients on NSAIDs or corticosteroids, and stress ulcer prophylaxis (in secondary care).

Communication is poor. In one UK centre, suggested duration of treatment was specified in fewer than $20 \%$ of hospital discharge letters, less than one-third indicated that prescriptions needed to be reviewed, and only half contained information as to why the drug was started ${ }^{26}$.

Overprescribing is more common in those with increasing numbers of comorbidities and polypharmacy, likely due in part to a belief that PPIs have greater benefits and safety profiles than have actually been demonstrated. Additionally, patients receiving multiple medicines are likely to see several specialists. This increases the chance of a drug being prescribed and renders it less likely that one clinician takes overall responsibility for the therapeutic repertoire or questions a prescription from a colleague. A number of cognitive biases come into play, including a preference to maintain the status quo, and fear of criticism should harm arise because of a perceived (if justified) omission ${ }^{27}$.

One further specific problem is that, once a patient has taken a PPI for any more than a few weeks, acid hypersecretion can occur on discontinuation. This causes rebound symptoms, and frequently establishes a vicious cycle of drug reinitiation and long-term continuation ${ }^{28}$. 


\section{Harms of PPI therapy}

Over the past decade, a range of adverse effects from PPI therapy have been identified. Although most studies are retrospective, a signal has evolved that PPIs are not as benign as originally perceived. Most of these translate into small absolute risks at an individual level, but because of prevalence and chronic use contribute substantial population attributable risk.

The most widely studied and publicised of these is Clostridium difficile infection. A meta-analysis of 23 cohort and case-control studies, involving almost 300,000 patients, identified a $65 \%$ increase in the relative risk of $C$. difficile-associated diarrhoea ${ }^{29}$. The mechanism remains unproven, but may be that acid suppression permits viability of the $C$. difficile vegetative state, subsequently leading to clinically symptomatic infection. There are suggestions that PPIs also increase risks of Campylobacter and Salmonella gastroenteritis (both are acidsensitive organisms) ${ }^{30}$, and two recent studies demonstrate alterations in the gut microbiome ${ }^{31}$.

PPIs have been provisionally associated with increased risk of pneumonia (odds ratio on meta-analysis $1.27 \%)^{32}$. The proposed mechanism relates to acid suppression permitting gastric bacterial overgrowth, leading to respiratory tract infection through reflux and micro-aspiration. The caveat is that most data derive from retrospective studies, and at least one prospective study failed to verify the association ${ }^{33}$.

Increased fracture risk has been reported, most notably in the Nurses Health Study, which included 79,899 female participants followed for eight years ${ }^{34}$. The age-adjusted hazard ratio of hip fracture was 1.35 with more than 2 years of PPI use, and even higher in smokers. Possible explanations include reduced calcium absorption ${ }^{35}$, or competition with osteoblast and osteoclast proton pumps that impedes bone remodelling ${ }^{36}$. Deficiencies have also been reported in both iron ${ }^{37}$ and vitamin $\mathrm{B}_{12}{ }^{38}$ absorption, and a major issue in a small subset of patients is severe hypomagnesaemia ${ }^{39}$. If the latter occurs it is typically a drug class effect, likely due to inhibition of cation transport in the colon.

PPIs are now well recognised as a cause of acute interstitial nephritis, which, in a nested case-control study of 572,661 patients, occurred with an odds ratio of 5.16 (translating into an incidence of 11.98 per 100,000 person-years) ${ }^{40}$. Early recognition and drug discontinuation are crucial for maximising renal recovery. There have also been a number of reports of PPIs triggering subacute cutaneous lupus erythematosus ${ }^{41}$.

Finally, increased rates of chronic kidney disease and myocardial infarction have recently been reported among PPI users. In one study of 173,321 people, the hazard ratio of developing chronic renal impairment was 1.22, rising with increasing duration of exposure ${ }^{42}$. In a further data-mining exercise examining records from 2.9 million patients, PPIs were associated with a 1.16-fold risk of myocardial infarction, and a 2 -fold increased risk of cardiovascular mortality ${ }^{43}$. The cause was not ascertained, and although the authors speculated about interference with nitric oxide signalling, an alternative explanation would be 
confounding due to increased use of acid suppression in patients with greater numbers of comorbidities and polypharmacy (and hence overall cardiovascular risk).

\section{Drug interactions}

The extensive, long-term use of PPIs in patients with multiple comorbidities and polypharmacy renders them high risk for drug-drug interactions. Specifically, their alteration of $\mathrm{pH}$ in the gastrointestinal tract can impact on drug absorption, and they inhibit (to varying degrees) cytochrome (CYP) p450 and the pglycoprotein pathway ${ }^{44}$. This may be a particular issue for omeprazole, which has high affinity for CYP2C19 and moderate affinity for CYP3A445.

Drug interactions were raised as a major concern in the case of clopidogrel, which requires CYP2C19 for conversion to its active metabolite. An initial randomised controlled trial of 140 patients found a reduction in the platelet reactivity index after one week in patients receiving clopidogrel with omeprazole $^{46}$, and on this basis a number of regulatory agencies counselled that both omeprazole and esomeprazole should be avoided in this context. The clinical relevance of the interaction has, however, been called into question, with the prospective COGENT trial reporting no increase in cardiovascular events in 3,761 patients on omeprazole and dual antiplatelet therapy ${ }^{47}$. The trial was terminated prematurely due to lack of funding but, while this did restrict statistical power, a subsequent review concluded that, with all currently available clinical data, despite evidence of an ex vivo interaction, the case for adverse impact in patients in vivo had not been made ${ }^{48}$.

Others have also highlighted the significant risk of bias in many of the retrospective studies reporting harmful interactions between PPIs and clopidogrel ${ }^{49}$, and pointed out that concomitant use does halve the risk of gastrointestinal bleeding 50 . Consequently, some authorities advocate preferential use of alternative PPIs with lower CYP2C19 affinity (such as pantoprazole or rabeprazole) in this patient cohort, although this strategy has not been subject to well-designed clinical trials.

Although studies on drug interactions have been dominated by those focusing on antiplatelet therapies, PPIs can also decrease plasma concentrations of several anti-retroviral agents, dabigatran, mycophenolate mofetil, and targeted oncological signal pathway inhibitors, as well as increase the concentrations of calcineurin inhibitors, methotrexate and metformin ${ }^{51}$. As with clopidogrel, little evidence has emerged to date that these result in clinically meaningful harm, although it would still be prudent to take care when prescribing PPIs with drugs that have potential for an interaction to occur.

\section{Minimising overprescribing}

The steps required to curb and subsequently reduce inappropriate prescribing include: recognition of the problem; use of alternative approaches to manage conditions currently treated "by default" with PPIs; education regarding appropriate indications and durations for their use; and enhanced drug stewardship akin to that employed widely for antimicrobials, mandating better 
documentation around PPI prescriptions and regular review. Patient involvement and shared decision-making are also key ${ }^{52}$.

One of the most frequent reasons for long-term PPI prescribing is dyspepsia. This is a condition that can often be significantly ameliorated by lifestyle modification or medication rationalisation ${ }^{3}$. Weight loss (if overweight) and smoking cessation should be strongly encouraged. Possible drug contributors to dyspepsia include calcium channel blockers, nitrates, theophyllines, bisphosphonates, antiplatelet agents and NSAIDs, and a therapeutics review should be conducted to consider whether these are still indicated or could be appropriately substituted. Where PPIs are prescribed, the lowest effective dose should be used, for the shortest possible duration. Low-cost PPIs should generally be used in preference to more expensive agents, although whether this extends to situations where drug-drug interactions could occur remains an open question. The indications and intended durations should be clearly documented and communicated to the primary care provider and pharmacy.

Patients on long-term therapy should be reviewed on (at minimum) an annual basis and, if the indication for treatment was dyspepsia, encouraged to stepdown therapy gradually, aiming for the lowest effective dose. Substitution of PPIs with antacid or alginate therapy, or $\mathrm{H}_{2}$ receptor antagonists, can also be considered. Patients should be counselled regarding rebound acid secretion on drug discontinuation, that this does not necessarily represent recurrence of disease, and on strategies to manage this (preferably without re-escalating PPI dose $)^{28}$.

The other common rationale for long-term PPI prescribing is prophylaxis when receiving antiplatelet agents or NSAIDs. Most guidelines suggest this is only required for high-risk patients, specifically those over 65 years of age, with a history of peptic ulcer disease or upper gastrointestinal haemorrhage, or taking multiple medicines that augment gastrointestinal adverse effects ${ }^{53,54}$. The latter include high-dose steroids (dose equivalent greater than $30 \mathrm{mg}$ prednisolone/day), anticoagulants, and selective serotonin reuptake inhibitors.

Time to deprescribe

Prescribing of PPIs has skyrocketed over the past decade. These drugs can be effective, but are principally intended for short-term use yet often not discontinued. There is clear and consistent evidence of overprescribing as clinicians overestimate benefits and underestimate harms, associated with substantial costs to healthcare providers. Measures should be put in place to educate prescribers as to appropriate indications and durations for PPI use, provide a degree of stewardship, and facilitate long-term users in de-escalating therapy.

Daniel J B Marks is a clinical pharmacologist at University College London Hospital and a postdoctoral research fellow at the Centre for Molecular Medicine, University College London

\section{References:}


1. Forgacs I, Loganayagam A. Overprescribing proton pump inhibitors. $B M J$ 2008; 336(7634): 2-3. 10.1136/bmj.39406.449456.BE http://www.ncbi.nlm.nih.gov/pubmed/18174564.

2. Dworzynski K, Pollit V, Kelsey A, Higgins B, Palmer K, Guideline Development G. Management of acute upper gastrointestinal bleeding: summary of NICE guidance. BMJ 2012; 344: e3412. 10.1136/bmj.e3412 http://www.ncbi.nlm.nih.gov/pubmed/22695897.

3. Ford AC, Moayyedi P. Dyspepsia. BMJ 2013; 347: f5059. 10.1136/bmj.f5059 http://www.ncbi.nlm.nih.gov/pubmed/23990632.

4. Graham DY, Fischbach L. Helicobacter pylori treatment in the era of increasing antibiotic resistance. Gut 2010; 59(8): 1143-53. 10.1136/gut.2009.192757 http://www.ncbi.nlm.nih.gov/pubmed/20525969.

5. Laine L. GI risk and risk factors of NSAIDs. J Cardiovasc Pharmacol 2006; 47 Suppl 1: S60-6. http://www.ncbi.nlm.nih.gov/pubmed/16785831.

6. Fitzgerald RC, di Pietro M, Ragunath K, et al. British Society of Gastroenterology guidelines on the diagnosis and management of Barrett's oesophagus. Gut 2014; 63(1): 7-42. 10.1136/gutjnl-2013-305372 http://www.ncbi.nlm.nih.gov/pubmed/24165758.

7. Neumann I, Letelier LM, Rada G, et al. Comparison of different regimens of proton pump inhibitors for acute peptic ulcer bleeding. Cochrane Database Syst Rev 2013; (6): CD007999. 10.1002/14651858.CD007999.pub2 http://www.ncbi.nlm.nih.gov/pubmed/23760821.

8. Hollingworth S, Duncan EL, Martin JH. Marked increase in proton pump inhibitors use in Australia. Pharmacoepidemiol Drug Saf 2010; 19(10): 1019-24. 10.1002/pds.1969 http://www.ncbi.nlm.nih.gov/pubmed/20623646.

9. Haastrup P, Paulsen MS, Zwisler JE, et al. Rapidly increasing prescribing of proton pump inhibitors in primary care despite interventions: a nationwide observational study. Eur J Gen Pract 2014; 20(4): 290-3. $10.3109 / 13814788.2014 .905535$ http://www.ncbi.nlm.nih.gov/pubmed/24779533.

10. McGowan B, Bennett K, Barry M, Canny M. The utilisation and expenditure of medicines for the prophylaxis and treatment of osteoporosis. Ir Med J 2008; 101(2): 38-41. http://www.ncbi.nlm.nih.gov/pubmed/18450246.

11. Ribolsi M, Savarino E, De Bortoli N, et al. Reflux pattern and role of impedance-pH variables in predicting PPI response in patients with suspected GERD-related chronic cough. Aliment Pharmacol Ther 2014; 40(8): 966-73. 10.1111/apt.12919 http://www.ncbi.nlm.nih.gov/pubmed/25109844.

12. Schepisi R, Fusco S, Sganga F, et al. Inappropriate Use of Proton Pump Inhibitors in Elderly Patients Discharged from Acute Care Hospitals. J Nutr Health Aging 2016; 20(6): 665-70. 10.1007/s12603-015-0642-5 http://www.ncbi.nlm.nih.gov/pubmed/27273358.

13. Haastrup PF, Rasmussen S, Hansen JM, Christensen RD, Sondergaard J, Jarbol DE. General practice variation when initiating long-term prescribing of proton pump inhibitors: a nationwide cohort study. BMC Fam Pract 2016; 17(1): 57. 10.1186/s12875-016-0460-9 http://www.ncbi.nlm.nih.gov/pubmed/27233634. 
14. Haastrup PF, Paulsen MS, Christensen RD, Sondergaard J, Hansen JM, Jarbol DE. Medical and non-medical predictors of initiating long-term use of proton pump inhibitors: a nationwide cohort study of first-time users during a 10-year period. Aliment Pharmacol Ther 2016; 44(1): 78-87. 10.1111/apt.13649 http://www.ncbi.nlm.nih.gov/pubmed/27137875.

15. van den Bemt PM, Chaaouit N, van Lieshout EM, Verhofstad MH. Noncompliance with guidelines on proton pump inhibitor prescription as gastroprotection in hospitalized surgical patients who are prescribed NSAIDs. Eur J Gastroenterol Hepatol 2016.

10.1097/MEG.0000000000000634 http://www.ncbi.nlm.nih.gov/pubmed/27046006.

16. Batuwitage BT, Kingham JG, Morgan NE, Bartlett RL. Inappropriate prescribing of proton pump inhibitors in primary care. Postgrad Med J 2007; 83(975): 66-8. 10.1136/pgmj.2006.051151 http://www.ncbi.nlm.nih.gov/pubmed/17267683.

17. Jarchow-Macdonald AA, Mangoni AA. Prescribing patterns of proton pump inhibitors in older hospitalized patients in a Scottish health board. Geriatr Gerontol Int 2013; 13(4): 1002-9. 10.1111/ggi.12047 http://www.ncbi.nlm.nih.gov/pubmed/23506515.

18. Pasina L, Nobili A, Tettamanti M, et al. Prevalence and appropriateness of drug prescriptions for peptic ulcer and gastro-esophageal reflux disease in a cohort of hospitalized elderly. Eur J Intern Med 2011; 22(2): 205-10. 10.1016/j.ejim.2010.11.009 http://www.ncbi.nlm.nih.gov/pubmed/21402255.

19. George CJ, Korc B, Ross JS. Appropriate proton pump inhibitor use among older adults: a retrospective chart review. Am J Geriatr Pharmacother 2008; 6(5): 249-54. 10.1016/j.amjopharm.2008.12.001 http://www.ncbi.nlm.nih.gov/pubmed/19161927.

20. Pohland CJ, Scavnicky SA, Lasky SS, Good CB. Lansoprazole overutilization: methods for step-down therapy. Am J Manag Care 2003; 9(5): 353-8. http://www.ncbi.nlm.nih.gov/pubmed/12744297.

21. Thomas L, Culley EJ, Gladowski P, Goff V, Fong J, Marche SM. Longitudinal analysis of the costs associated with inpatient initiation and subsequent outpatient continuation of proton pump inhibitor therapy for stress ulcer prophylaxis in a large managed care organization. J Manag Care Pharm 2010; 16(2): 122-9. 10.18553/jmcp.2010.16.2.122 http://www.ncbi.nlm.nih.gov/pubmed/20178397.

22. Van Soest EM, Siersema PD, Dieleman JP, Sturkenboom MC, Kuipers EJ. Persistence and adherence to proton pump inhibitors in daily clinical practice. Aliment Pharmacol Ther 2006; 24(2): 377-85. 10.1111/j.13652036.2006.02982.x http://www.ncbi.nlm.nih.gov/pubmed/16842465.

23. van Vliet EP, Otten HJ, Rudolphus A, et al. Inappropriate prescription of proton pump inhibitors on two pulmonary medicine wards. Eur J Gastroenterol Hepatol 2008; 20(7): 608-12. 10.1097/MEG.0b013e3282f52f95 http://www.ncbi.nlm.nih.gov/pubmed/18679061.

24. Heidelbaugh JJ, Goldberg KL, Inadomi JM. Magnitude and economic effect of overuse of antisecretory therapy in the ambulatory care setting. $\mathrm{Am} \mathrm{J}$ 
Manag Care 2010; 16(9): e228-34.

http://www.ncbi.nlm.nih.gov/pubmed/21250399.

25. van Vliet EP, Steyerberg EW, Otten HJ, et al. The effects of guideline implementation for proton pump inhibitor prescription on two pulmonary medicine wards. Aliment Pharmacol Ther 2009; 29(2): 213-21.

10.1111/j.1365-2036.2008.03875.x http://www.ncbi.nlm.nih.gov/pubmed/19006542.

26. Walker NM, McDonald J. An evaluation of the use of proton pump inhibitors. Pharm World Sci 2001; 23(3): 116-7.

http://www.ncbi.nlm.nih.gov/pubmed/11468876.

27. Anderson K, Stowasser D, Freeman C, Scott I. Prescriber barriers and enablers to minimising potentially inappropriate medications in adults: a systematic review and thematic synthesis. BMJ Open 2014; 4(12): e006544. 10.1136/bmjopen-2014-006544 http://www.ncbi.nlm.nih.gov/pubmed/25488097.

28. Reimer C, Sondergaard B, Hilsted L, Bytzer P. Proton-pump inhibitor therapy induces acid-related symptoms in healthy volunteers after withdrawal of therapy. Gastroenterology 2009; 137(1): 80-7, 7 e1. 10.1053/j.gastro.2009.03.058 http://www.ncbi.nlm.nih.gov/pubmed/19362552.

29. Janarthanan S, Ditah I, Adler DG, Ehrinpreis MN. Clostridium difficileassociated diarrhea and proton pump inhibitor therapy: a meta-analysis. Am J Gastroenterol 2012; 107(7): 1001-10.10.1038/ajg.2012.179 http://www.ncbi.nlm.nih.gov/pubmed/22710578.

30. Leonard J, Marshall JK, Moayyedi P. Systematic review of the risk of enteric infection in patients taking acid suppression. Am J Gastroenterol 2007; 102(9): 2047-56; quiz 57. 10.1111/j.1572-0241.2007.01275.x http://www.ncbi.nlm.nih.gov/pubmed/17509031.

31. Imhann F, Bonder MJ, Vich Vila A, et al. Proton pump inhibitors affect the gut microbiome. Gut 2016; 65(5): 740-8. 10.1136/gutjnl-2015-310376 http://www.ncbi.nlm.nih.gov/pubmed/26657899.

32. Eom CS, Jeon CY, Lim JW, Cho EG, Park SM, Lee KS. Use of acid-suppressive drugs and risk of pneumonia: a systematic review and meta-analysis. CMAJ 2011; 183(3): 310-9.10.1503/cmaj.092129 http://www.ncbi.nlm.nih.gov/pubmed/21173070.

33. Filion KB, Chateau D, Targownik LE, et al. Proton pump inhibitors and the risk of hospitalisation for community-acquired pneumonia: replicated cohort studies with meta-analysis. Gut 2014; 63(4): 552-8. 10.1136/gutjnl2013-304738 http://www.ncbi.nlm.nih.gov/pubmed/23856153.

34. Khalili H, Huang ES, Jacobson BC, Camargo CA, Jr., Feskanich D, Chan AT. Use of proton pump inhibitors and risk of hip fracture in relation to dietary and lifestyle factors: a prospective cohort study. BMJ 2012; 344: e372. 10.1136/bmj.e372 http://www.ncbi.nlm.nih.gov/pubmed/22294756.

35. Graziani G, Como G, Badalamenti S, et al. Effect of gastric acid secretion on intestinal phosphate and calcium absorption in normal subjects. Nephrol Dial Transplant 1995; 10(8): 1376-80. http://www.ncbi.nlm.nih.gov/pubmed/8538929.

36. Costa-Rodrigues J, Reis S, Teixeira S, Lopes S, Fernandes MH. Dosedependent inhibitory effects of proton pump inhibitors on human 
osteoclastic and osteoblastic cell activity. FEBS J 2013; 280(20): 5052-64. 10.1111/febs.12478 http://www.ncbi.nlm.nih.gov/pubmed/23937530.

37. McColl KE. Effect of proton pump inhibitors on vitamins and iron. Am J Gastroenterol 2009; 104 Suppl 2: S5-9. 10.1038/ajg.2009.45

http://www.ncbi.nlm.nih.gov/pubmed/19262546.

38. Lam JR, Schneider JL, Zhao W, Corley DA. Proton pump inhibitor and histamine 2 receptor antagonist use and vitamin B12 deficiency. JAMA 2013; 310(22): 2435-42. 10.1001/jama.2013.280490 http://www.ncbi.nlm.nih.gov/pubmed/24327038.

39. Hess MW, Hoenderop JG, Bindels RJ, Drenth JP. Systematic review: hypomagnesaemia induced by proton pump inhibition. Aliment Pharmacol Ther 2012; 36(5): 405-13. 10.1111/j.1365-2036.2012.05201.x http://www.ncbi.nlm.nih.gov/pubmed/22762246.

40. Blank ML, Parkin L, Paul C, Herbison P. A nationwide nested case-control study indicates an increased risk of acute interstitial nephritis with proton pump inhibitor use. Kidney Int 2014; 86(4): 837-44. 10.1038/ki.2014.74 http://www.ncbi.nlm.nih.gov/pubmed/24646856.

41. Sandholdt LH, Laurinaviciene R, Bygum A. Proton pump inhibitor-induced subacute cutaneous lupus erythematosus. Br J Dermatol 2014; 170(2): 342-51. 10.1111/bjd.12699 http://www.ncbi.nlm.nih.gov/pubmed/24547721.

42. Xie Y, Bowe B, Li T, Xian H, Balasubramanian S, Al-Aly Z. Proton Pump Inhibitors and Risk of Incident CKD and Progression to ESRD. J Am Soc Nephrol 2016. 10.1681/ASN.2015121377 http://www.ncbi.nlm.nih.gov/pubmed/27080976.

43. Shah $\mathrm{NH}$, LePendu P, Bauer-Mehren A, et al. Proton Pump Inhibitor Usage and the Risk of Myocardial Infarction in the General Population. PLoS One 2015; 10(6): e0124653. 10.1371/journal.pone.0124653 http://www.ncbi.nlm.nih.gov/pubmed/26061035.

44. Polasek TM, Lin FP, Miners JO, Doogue MP. Perpetrators of pharmacokinetic drug-drug interactions arising from altered cytochrome P450 activity: a criteria-based assessment. Br J Clin Pharmacol 2011; 71(5): 727-36. 10.1111/j.1365-2125.2011.03903.x http://www.ncbi.nlm.nih.gov/pubmed/21223357.

45. Li W, Zeng S, Yu LS, Zhou Q. Pharmacokinetic drug interaction profile of omeprazole with adverse consequences and clinical risk management. Ther Clin Risk Manag 2013; 9: 259-71. 10.2147/TCRM.S43151 http://www.ncbi.nlm.nih.gov/pubmed/23745048.

46. Gilard M, Arnaud B, Cornily JC, et al. Influence of omeprazole on the antiplatelet action of clopidogrel associated with aspirin: the randomized, double-blind OCLA (Omeprazole CLopidogrel Aspirin) study. J Am Coll Cardiol 2008; 51(3): 256-60. 10.1016/j.jacc.2007.06.064 http://www.ncbi.nlm.nih.gov/pubmed/18206732.

47. Bhatt DL, Cryer BL, Contant CF, et al. Clopidogrel with or without omeprazole in coronary artery disease. N Engl J Med 2010; 363(20): 190917. 10.1056/NEJMoa1007964 http://www.ncbi.nlm.nih.gov/pubmed/20925534.

48. Focks JJ, Brouwer MA, van Oijen MG, Lanas A, Bhatt DL, Verheugt FW. Concomitant use of clopidogrel and proton pump inhibitors: impact on 
platelet function and clinical outcome- a systematic review. Heart 2013;

99(8): 520-7. 10.1136/heartjnl-2012-302371

http://www.ncbi.nlm.nih.gov/pubmed/22851683.

49. Lima JP, Brophy JM. The potential interaction between clopidogrel and proton pump inhibitors: a systematic review. BMC Med 2010; 8: 81. 10.1186/1741-7015-8-81

http://www.ncbi.nlm.nih.gov/pubmed/21134261.

50. Siller-Matula JM, Jilma B, Schror K, Christ G, Huber K. Effect of proton pump inhibitors on clinical outcome in patients treated with clopidogrel: a systematic review and meta-analysis. J Thromb Haemost 2010; 8(12): 2624-41. 10.1111/j.1538-7836.2010.04049.x http://www.ncbi.nlm.nih.gov/pubmed/20831618.

51. Yucel E, Sancar M, Yucel A, Okuyan B. Adverse drug reactions due to drugdrug interactions with proton pump inhibitors: assessment of systematic reviews with AMSTAR method. Expert Opin Drug Saf 2016; 15(2): 223-36. 10.1517/14740338.2016.1128413 http://www.ncbi.nlm.nih.gov/pubmed/26635063.

52. Reeve E, Shakib S, Hendrix I, Roberts MS, Wiese MD. Review of deprescribing processes and development of an evidence-based, patientcentred deprescribing process. Br J Clin Pharmacol 2014; 78(4): 738-47. 10.1111/bcp.12386 http://www.ncbi.nlm.nih.gov/pubmed/24661192.

53. Bhatt DL, Scheiman J, Abraham NS, et al. ACCF/ACG/AHA 2008 expert consensus document on reducing the gastrointestinal risks of antiplatelet therapy and NSAID use. Am J Gastroenterol 2008; 103(11): 2890-907. 10.1111/j.1572-0241.2008.02216.x http://www.ncbi.nlm.nih.gov/pubmed/18853965.

54. Lanza FL, Chan FK, Quigley EM, Practice Parameters Committee of the American College of G. Guidelines for prevention of NSAID-related ulcer complications. Am J Gastroenterol 2009; 104(3): 728-38. 10.1038/ajg.2009.115 http://www.ncbi.nlm.nih.gov/pubmed/19240698. 